\title{
Issues of Globalization and Localization in Youth Culture: The Case of Memes
}

\author{
Michela Canepari ${ }^{1}$ \\ ${ }^{1}$ Languages Unit, Department of Humanities, Social Sciences and Cultural Industries, University of Parma, \\ Parma, Italy
}

\begin{abstract}
.
The present article aims at studying the phenomenon of memes as a communicative, social and cultural product, in the attempt to identify the level of globalisation vis à vis localisation of the cultures and the societies that produce them. To this end, the article presents some memes from both the United Kingdom and Italy, which were collected in a rather large corpus, and briefly analyses them from a linguistic and visual perspective. For reasons of space, the quantitative analysis of the corpus will not be discussed at length here, even though the results of the study will be indicated briefly. However, the qualitative analysis of some of the memes will prove that a large part of the existing material - while adopting various features of globalisation - often exploits, from a linguistic point of view, regional variants of the language adopted. Thus, since language is the expression of specific cultures, the analysis demonstrates how, despite globalisation, local (and localised) features of communities and cultures keep existing in their uniqueness. Hence, since memes are, as indicated in the title of this paper, a privileged form of communication among younger members of society, the results point to a generation of youth that, despite the tendency to follow global models, is well aware of the traditional and local cultures they stem from and strive to keep them alive. On the basis of this analysis, the article finally argues that memes - like many other products of popular culture - represent a privileged arena which, if studied systematically through the tools of discourse analysis and sociolinguistics, could reveal important aspects of the societies that produce them and their evolution.
\end{abstract}

Keywords: culture; dialects; food; tradition; visual design

\footnotetext{
${ }^{1}$ See for instance: Gatherer, D. (1998). Meme pools, World 3, and Averroes's vision of immortality. Zygon: Journal of Religion\&Science, vol. 33 (2), pp. 203- 219.Doyle, B. (2006). Memography and the Memetic Web.
} 


\section{Introduction}

\subsection{Purposes}

Since memes heavily rely on the social media, they can be easily identified as forms of communication typical of younger generations of digital natives, and - despite the scarcity of academic studies on the topic ${ }^{1}$ - can therefore become important artefacts to be examined, in

order to shed some light on the dynamics that determine the evolution of our societies and, more specifically, the development of youth culture and it language(s). The memes this article is going to take into consideration are therefore those "picture[s] with a short caption which is a caricature illustration of current political, sports, and cultural events" (Górka, 2014: 226). Yet, some of the memes selected as a corpus of analysis for this article will demonstrate that Górka's statements, according to which memes, as ironic and parodic forms of expression, often contradict common and officially accepted norms and rules (ivi: 232), does not always correspond to the truth. Indeed, the specific aim of this paper is to evaluate the extent to which some of the memes available in different countries comply with globalisation (thereby contributing to it) or somehow resist it. Naturally, the categories of memes are many, and it is undoubtful that the level of globalisation and/or localisation depends on the context in which they are produced, their illocutionary function and their perlocutionary effect. In spite of this, it is possible to identify some common features which all memes share: the presence of a visual; the humoristic use of language; the introduction of cultural references. In this context, the adjective "cultural" can naturally mean very different things and point to extremely different realities, which can be understood in terms of the original division between high/visible culture and low/invisible culture (Hall, 1984 [1959]; Brake et al., 1995) only partially.

\subsection{Methodology}

Given the incredible number of memes available on the internet, the choice of the corpus of analysis was particularly challenging. In order to collect materials that could lead to meaningful results, I clearly had to make very selective choices which were, at least partially, personal. Thus, during the compilation of the corpus, I tried to be as systematic as possible, identifying various categories of memes (one of which was then selected for extended analysis in this article), in the attempt to see how these topics are approached in the memes originating from different countries and, when possible, different towns. Corpus linguistics was thus used to study the corpus from a quantitative point of view, whereas notions from sociolinguistics, pragmatics and critical discourse analysis were utilised to analyse, albeit briefly, the corpus from a qualitative perspective. Clearly, because of space constraints, the analysis presented here is very succinct. Nevertheless, I hope this paper can suggest at least some of the many implications entailed by a next-gen form of communication such as memes.

\subsection{For a definition of meme}

The word "meme" was coined in 1976 by British scientist Richard Dawkins in his The Selfish Gene (Dawkins, 1976), where he defined it as "a unit of cultural transmission". The word, which derives from the Greek root "mim-", meaning "to imitate", "to mimic", recalls, from a phonological point of view, the word "gene". This is the reason why the author opted for this word, rather than the alternative "mimeme", which he had initially considered (Dawkins, 1976). 
As we read in the Cambridge Dictionary, in fact, "a meme is the cultural equivalent of the unit of physical heredity, the gene" (online), though it identifies a cultural feature or a type of behaviour that is passed from one generation to another, and can refer to various types of products. In Dawkins's words,

EContent, vol. 29 (1), 25; Shifman, L. (2013). MIT Press Essential Knowledge: Memes in Digital Culture. Cambridge, Massachusetts: MIT Press, pp. 17- 36.

Examples of memes are tunes, ideas, catch-phrases, clothes fashions, ways of making pots or of building arches. Just as genes propagate themselves in the gene pool by leaping from body to body via sperms or eggs, so memes propagate themselves in the meme pool by leaping from brain to brain via a process which, in the broad sense, can be called imitation [...] (Dawkins, 1976)

With time, memes have come to indicate "an amusing or interesting item (such as a captioned picture or video) or genre of items that is spread widely online, especially through social media" (Merriam-Webster Dictionary, online). These are precisely the products this article is investigating, to demonstrate how they implicitly become important elements in the "struggle for recognition" of Hegelian memory (Hegel, 1977, p. 311).

\section{Analysing the corpus}

\subsection{Findings}

This article thus approaches the topic of "food", taking into consideration memes originating in two countries, namely the United Kingdom and Italy. The category of food appears in fact particularly interesting, since culinary traditions exemplify men's values and their taboos. As a consequence, the preparation and consumption of food can be seen as cultural and social phenomena which, as some of the memes analysed here well testify, can become discriminating factors between different communities. Food, then, can be considered an important factor in the formation and preservation of cultural identity. Yet, although Hall would define this category as "high culture", the food that specific communities consume, the way they prepare it and the symbolic values it acquires, turn it into one of the invisible aspects of culture that Brake et al. (1995) describe: The quest for food has shaped the development of our society [...] Food and the science of food touches our lives in numerous ways. Many religions follow strict dietary laws. Some of the earliest observations in the world of chemistry came from the preparation and cooking of food. [...] Even class distinctions in some societies are determined by what foods are put on the table (Center for Human Nutrition, online).

\subsection{United Kingdom:}

\subsubsection{County of Yorkshire}

Despite stereotypical representations of British cuisine, the memes presented here point to the existence, in the United Kingdom too, of some traditional dishes. For instance, Figures 1-3 testify to the popularity (with both celebrities and ordinary people) of the small round side dish, generally used as a complement to roast meats, known as Yorkshire pudding: 
Figure 1: The Queen and Yorkshire Pudding

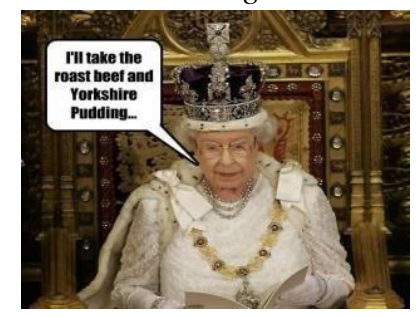

Source:https://cheezburger.com/2 $\underline{309094656}$
Figure 2: Sean Bean and Yorkshire pudding

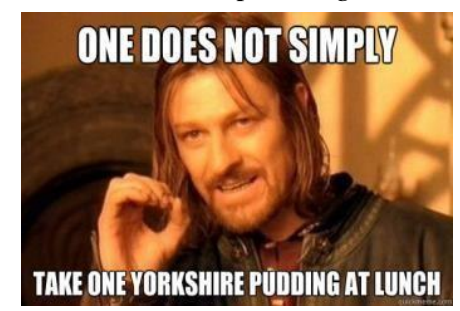

Source:http://www.quickmeme.c om/meme/368voc
Figure 3: Yorkshire pudding

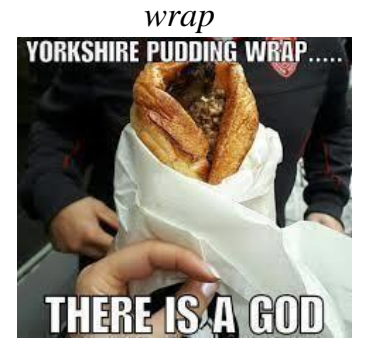

Source: https://www.facebook.com/s

traightupyorkshire/photos/a.5205

30451484937/812454148959231

Indeed, the exploitation of famous celebrities such as British actor Sean Bean - who adapts the famous quote "One does not simply walk into Mordor", uttered by the character he played in 2001 in the intersemiotic translation of J.R.R. Tolkien's The Lord of the Rings (1954) - and the Queen herself, finds its apotheosis in the third figure. The appreciation of the traditional pudding does in fact intensify in the third meme. From the secular world represented by Elizabeth II, the traditional dish enters the epic world of Boromir, from Tolkien's novel, and finally reaches an even higher, mystic level in the third image, where we find the explicit mention of God.

Naturally, the insertion of the word "God" entails many consequences, and implicitly testifies to the "heavenly" and "divine" nature of Yorkshire pudding. Thus, whereas the first to memes mainly rely on images and, through visual intertextuality, convey the reputation of the dish, in the third one, the visual is rather uncredited, as both the illocutionary force and the perlocutionary effect are realised via verbal language.

\subsubsection{Scotland}

The attitude towards traditional cuisine we can find in Scottish memes is however very different. Indeed, whereas Yorkshire memes pay tribute to the traditional dish, their Scottish counterpart often adopt a very ironic key, based on both verbal and visual language, to suggest - as in Figures 4 and 5 - the (scarce) quality of their culinary tradition, thereby confirming existing stereotypes:

Figure 4: ironic comment on Scottish culinary habit

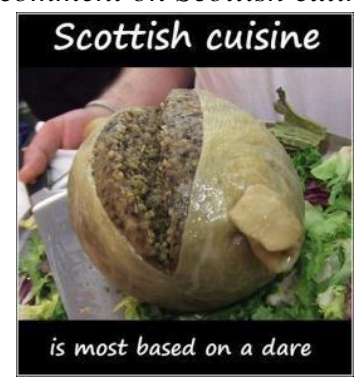

Source:https://www.pinterest.co.uk/pin/542894930056 216654/?nic=1\&nic $=1$ a
Figure 5: ironic representation of Scottish cuisine

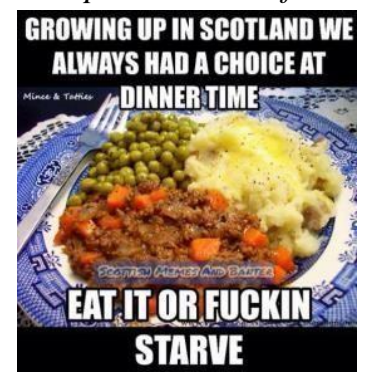

Source: https://me.me/i/growing-up-in-scotland-wealways-had-a-choice-at-19631873

However, the same character exploited above is employed in the following meme to suggest that there is more to Scottish cuisine than the "haggis" represented in figure 4. Unsurprisingly enough, in Figure 6, the category of "food" appears together with that of "dress code", thereby 
identifying two of the most important elements of visible culture (Brake et al., 1995). Yet, as the first meme below suggests, food can and does become a marker of invisible culture too. First of all, it should be noted that, in the other memes retrieved for this study, and despite Bean's verbal message, almost no indication of traditional cookery is suggested, other than the "savoury pudding containing sheep's pluck, minced with onion, oatmeal, suet, spices, and salt, mixed with stock, and cooked while traditionally encased in the animal's stomach" (Oxford English Dictionary, 2005). This aspect clearly appears extremely significant per se, in that it demonstrates the absence of a strong culinary tradition and a "taste" that might strike nonScottish people as rather peculiar. Actually, this is the implicit message of the meme depicted below in Figure 7, which is very telling indeed. In fact, this meme ironically celebrates, once again, the (bad) taste of Scottish people in the kitchen, given the mixture of ingredients which are usually conceived as incompatible:

Figure 6: Sean Bean and Scottish cuisine

Source:https://imgflip.com/i/32xdge

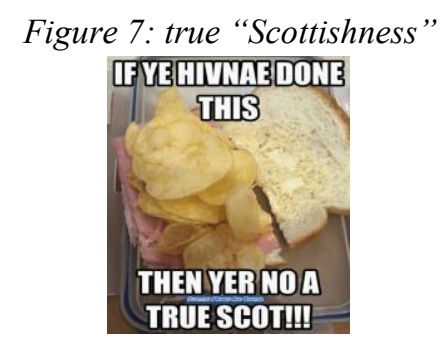

Source: https://me.me/i/yehivnaedone-this-then-yernoa-true-scot-love-it-\%E2\%9D\%A4\%EF\%B8\%8F9595798

However, the meme pragmatically conveys other meaning too. First of all, in the last image we can observe an implicit connection to the semantic field of "dare" exploited in the previous memes, which naturally suggests the brave character of true Scottish people. The most interesting aspect of this meme, however, is that it presents a Scottish linguistic variant. In reality, the intrusion of Scottish dialect is kept to a minimum and essentially involves the phonological level, relying on linguistic forms which can be easily translated intralinguistically into standard English. Yet, this exploitation of non-standard forms in the verbal message, serves the purpose of bringing forth Scottish (linguistic) identity. This, almost in defience of the fact that the combination of crisps and potatos with starchy products such as bread and pizza, originated in the U.S. and England, and could therefore beg the question of (neo) colonialism, globalisation and the power that certain nations still exercise onto other ones. However, historically people from Scotland have always been characterised by a strong sense of reselience as well as independence and resistance, a series of qualities epitomised by the figure of $13^{\text {th }}$ century warrior William Wallace, better known as Braveheart, who led the Scots against King Edward I in the first war of Independence. To this day, Scots - as the memes represented in Figures 8 and 9 testify, posit themeselves as strong and sturdy people, who can keep up despite the difficulties life might throw at them: 
Figure 8: Scottish tenacity

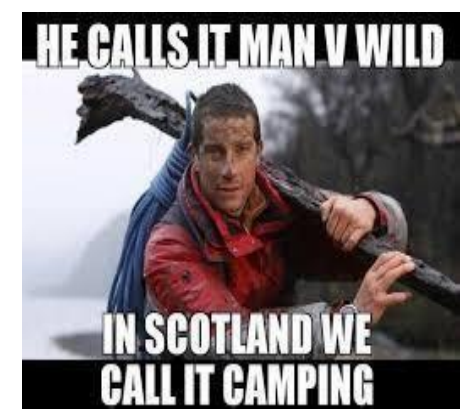

Figure 9: Scottish endurance

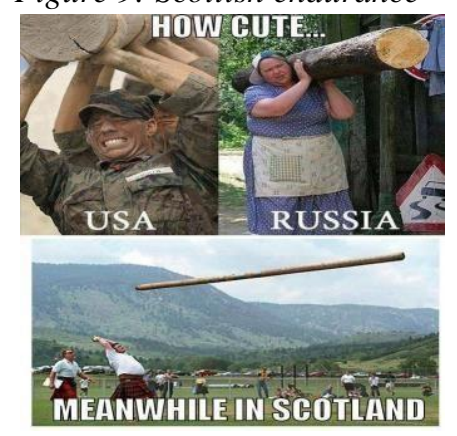

Source: https://www.pinterest.it/pin/42988272 Source: https://hugelol.com/lol/591341 Thus, memes such as

the one in Figure 9 - which, with ironic tones, brings to the fore some of the fundamental cultural aspects of this people (traditional dressing code and pastimes) - appear to create a balance between globalisation and localisation, and while using "ingredients" typical of our global world, as testified by the visual message, it manages to emphasise the local identity of this people, by exploiting, albeit rather mildly, linguistically non-standard forms. Thus, although the issue of linguistic variation would require a thorough analysis, which is not possible to develop here, it is nonetheless important to notice that the mention of food, clothes and language in memes such as those swiftly commented upon above, turn these into elements that, while being transparently visible, partake also in the most invisible layer of culture, therefore conveying a true sense of "Scottishness".

\subsection{Italy}

\subsubsection{Emilia Romagna}

Naturally, the culinary tradition of the whole of Italy is very strong, even though British cuisine too is characterised by various dishes, besides the Yorkshire pudding above (see for instance Ploughman's Lunch, Cornish pasties, apple crumble, jacked potatoes, Shepard's Pie etc.). Yet, in Italy, each region is renowned for its peculiar specialties: canederli from Trentino, polenta from Valle d'Aosta, trofie with pesto from Liguria, carbonara pasta from Lazio, cassata or arancini from Sicily, ${ }^{2}$ etc. Within this scenario, Emilia Romagna stands out for its richness in terms of food, and within the same region, each area/town/village has its own typical dish or a variant of the same dish which distinguishes itself from the neighbouring villages/towns. Clearly, being Italy a country where the notion of campanilismo is still very much present, we often witness a true fight between different regions/towns in an attempt to determine which one can claim the most delicious dishes.

${ }^{2}$ For a description of the ingredients and the preparation of these and other typical dishes please go to: https://www.cookingwithnonna.com/italian-recipes-food-and-cuisine.html. 


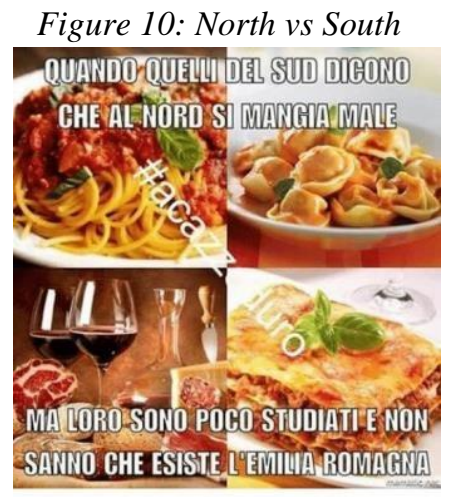

Source: https://me.me/i/quando-ouelli-del-sud-diconocheal-nord-si-mangia-male-13631586

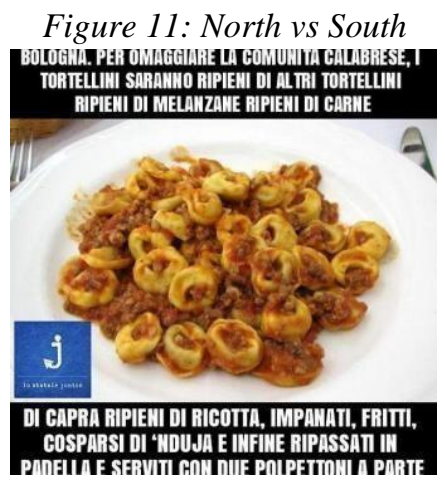

Source:

https://www.instazu.com/tag/polpettone

The meme in Figure 13, for instance, on the backdrop of a series of traditional dishes, recites: "When people from the South state that in the northern regions you cannot eat well, but they are not educated enough and ignore the existence of Emilia Romagna". What is peculiar about the verbal language exploited in this text is the form sono poco studiati, which is an ironic criticism of a typical regionalism from the South, through which the standard, active form non hanno studiato ("they have not studied enough") becomes a passive form ("They are not studied"). In the second meme as well - which reads "Bologna: In order to pay tribute to the community from Calabria, the dish of tortellini [typical of the town from Emilia Romagna] will be stuffed with extra tortellini, stuffed with aubergines, stuffed with goat meat, stuffed with ricotta cheese, coated with eggs and breadcrumbs and then fried, coated with the cured meat of "nduja, and then fried again and served with two side polpettones" - the approach is rather sarcastic, and emphasises Southerners' love for extremely rich foods, heavily fried and difficult to digest. That each region should be very jealous of its traditions and often celebrate its own to the detriment of the others doesn't therefore come as a surprise. Not only this but, as the memes above emphasise, this implicit criticism of Others is carried out by referring not only to the semantic field of food, but by attacking other regional peculiarities too, such as the use of linguistic nonstandard forms.

\subsubsection{Piacenza}

If we analyse the various memes from different towns from the same region, however, we can observe the very same mechanism at work. This is for instance the case with Piacenza and nearby towns such as Parma and Cremona, which are regularly targeted by the inhabitants of the former on more than one level. For example, in the first meme below, the tendency of the city of Parma to steal the products originating from the area near Piacenza (in particular the cured pork meat known as coppa) and pass it off as its own is ironically described. In Figure

12, in fact, this representation of Parma is extremely explicit, since the karateka from Piacenza uses the dialect word lädar (dialect form for "thief") to refer to the Pramšan (dialect for "inhabitant of Parma"), adding, in the bottom line highlighted in red, "hands off our coppa". 
Naturally, these choices of colours are very significant as well. One the one hand, the colour red of this line emphasises the urgency of the message, simultaneously creating a strong visual cohesion with the top part of the meme. On the other hand, since this is the prevalent colour in the coat of arms of the town of Piacenza, it works as a strong cultural marker, thus creating a cumulative effect with the other cultural markers exploited in the image (namely the coppa itself and the dialect used). In addition, bearing in mind the grammar of visual design elaborated by Kress and Leeuwen (2006, p. 186), it appears evident that the colour of Piacenza and one of its finest products, by occupying the top part of the image, represent the "ideal" situation the meme represents. Moreover, by resorting to dialect, in a similar way to the representation of Scottish pronunciation above, the culture of the town of Piacenza is further emphasised. On this occasion, however, we do not have only an orographic representation of the way certain words are pronounced, but actual dialect is adopted both at a lexical and a syntactic level (for instance, the noun ladär substitutes the Italian ladro, whereas the possessive adjective nòssa replaces the Italian nostra, for "our").

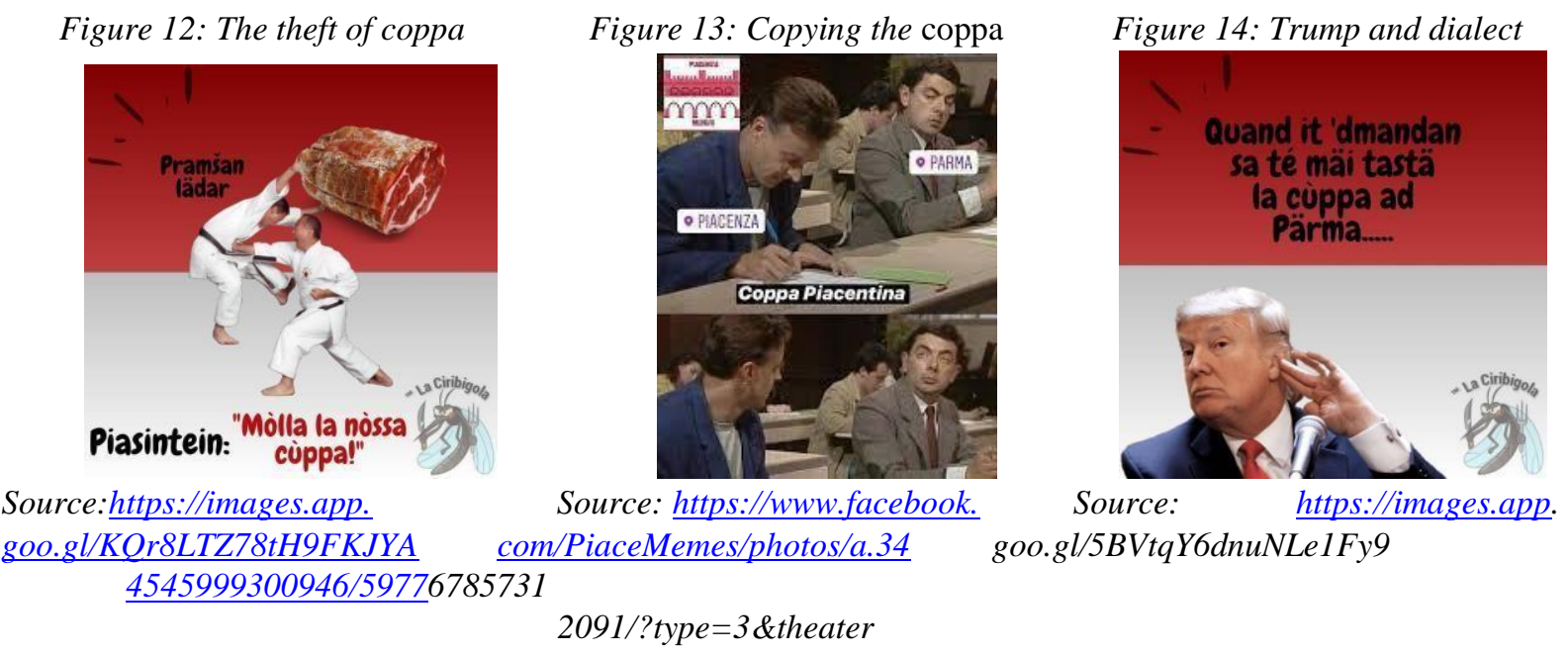

In Figure 13, through visual intertextuality, the meme recalls the famous scene where Mr. Bean tries to copy at an exam. Thus, the internationality of the character is ironically exploited to underline the attempts made by Parma to copy the traditional products from Piacenza, thus bringing together international and provincial elements. Finally, the global and the local are even more closely connected in the following meme, which appears extremely revealing. Indeed, the fact that this meme exploits the image of Donald Trump, President of the country that has made globalisation a reality, is extremely telling. In actual fact, since the American President appears in a message which exploits dialect in the caption (translated as: "When people ask you whether you have ever tasted the coppa from Parma"), this meme manages to convey several meanings at once: it suggests for instance that the feud between the towns of Parma and Piacenza as to which one has the best coppa is so important that even the U.S. President knows about it; more specifically, it puts forward that even President Trump knows that the "real coppa" is from Piacenza and not from Parma; it insinuates that globalisation which President Trump here embodies - cannot in reality obliterate localisation, here embodied by the product itself and the dialect used.

Certainly, the culinary tradition of Piacenza is very deeply rooted and long-standing, so that simply by skimming the various memes available, the importance that food acquires in the life of its inhabitants becomes apparent (approximately $87 \%$ of the existing memes are about food). 
Indeed, all aspects that play an important role in the life of a person are often connected to the world of food and discussed in association with the culinary products that have made this town famous. Thus, the various semantic fields are juxtaposed (either verbally or visually), and coexist:

Figure 15: coppa and the Champions League

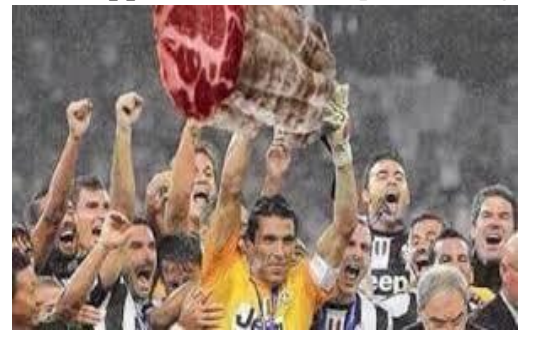

Figure 16: coppa and the World Cup

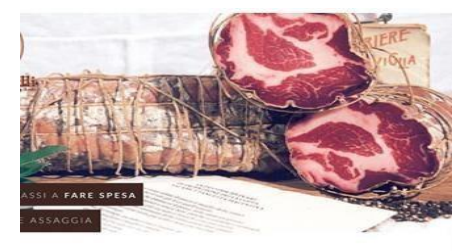

NON GIOCHEREMO AI MONDIALI

MA LA VERA COOPPA
CE L'ABBIAMO NO

Source: https://www.gazzetta.it/Calcio/Champions-Source: https://authgram.com/tag/co

League/Finale2015/07-06-2015 ppapiacentinadop

In both the memes above, the homophony of the word coppa (as cured meat), and the word coppa (cup), is exploited to create a pun which - as in the best hybrid texts - relies on both phonological and visual elements. For instance, in the first meme, the visual is selfexplicatory, in that the cured meat is substituted to the actual cup that goalkeeper Gigi Buffon (from the Italian football team Juventus) would have carried, had the Italian team won the final of the Champions League in 2015. In reality, on that occasion, the final was won by the Barcelona team. Thus, the ironic implicature of the message is that, on that occasion, the only cup Italians could bring home was the cured meat, since the actual silver cup went to the Spanish team. In the second meme, the play on words is basically the same, in that the verbal message reads "We're not going to play in the [2018] World Cup. Yet, we have the real coppa". The memes above therefore implicitly point to the fact that although football plays a major role in the life of Italians and their culture, traditional food is deemed even more central and is considered the fundamental element which gives some balance to the ups and downs of life. This is what happens with relationships too. As we can see in figure 17, given the opportunity to have a relationship with a girl, the male character represented here refuses to go out with her, on the ground that she does not like one of the most traditional dishes from Piacenza, namely tortelli. ${ }^{3}$ And although the protagonist of figure 18 manages to get a girlfriend, when she wants to engage in intercourse, he prefers to watch the recorded episode of a renown Italian television show dedicated to the various cured meats from Piacenza.

Figure 17: no tortelli no relationship

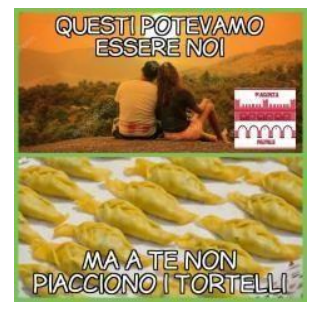

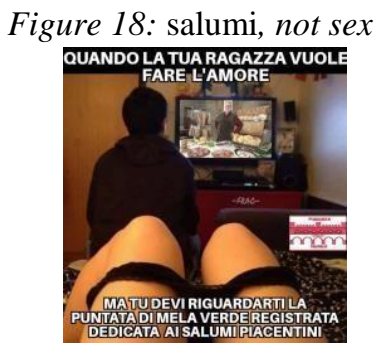

\footnotetext{
${ }^{3}$ Type of fresh pasta that is folded around a filling of ricotta cheese and spinach, boiled and served with butter, Parmisan cheese and sage.
} 
Source:https://www.facebook.com/PiaceMemes/photos_Source:https://www.facebook.com/PiaceMemes/photos la.344545999300946/586253308463546/?type $=3 \&$ the /a.344545999300946/551685595253651/?type=3\&the ater ater

Moreover, food infiltrates the discussion about climate change, and by exploiting the celebrity of an international figure such as Greta Thunberg, memes such as that reproduced in Figure 19 propound the idea that the typical dish of anolini ${ }^{4}$ should be reason enough to save the Earth, thereby suggesting the universal importance of this product which, although local, has an impact on the global world. In Figure 20, in addition, the representation of the conflict between the neighbouring towns of Piacenza and Cremona finds a place within the discussion of civil rights: indeed, the international flag of the LGBT movement is adapted to criticise the production of salame (another cured pork meat) by the town of Cremona, stating that "The only crime against nature is the salame from Cremona".

Figure 19: Global warming and anolini

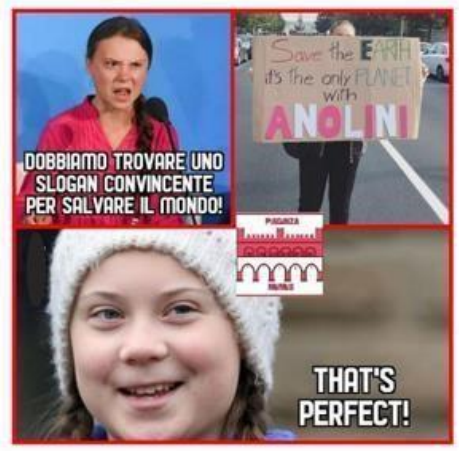

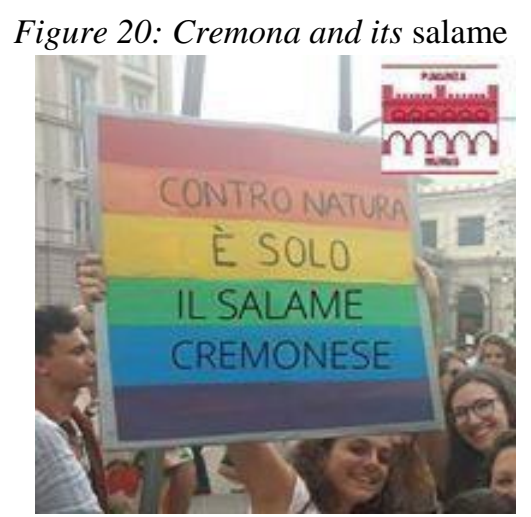

Source:https://www.instagram.com/p/B26TsZooxU Source:https://www.facebook.com/PiaceMemes/photos/a. cl? igshid=48uewnc3pvux 339 144983174381/701568770265332/?type=3\&theater

Food thus has a bearing in the global concerns which find a voice in Italian culture and actually permeates both domestic and foreign politics. Indeed, as we see in the first meme below, the crisis of the Italian Government - represented by Italian Ministers Luigi Di Maio and Matteo Salvini - is nothing compared to the crisis experienced when there are no more tortelli. Similarly, in the second meme, the impact of the controversial political decision to tax snacks is halved in the town of Piacenza, where children are brought up eating not prepackaged snacks but freshly baked rolls filled with either coppa or salame:

Figure 21: Di Maio, Slavini and tortelli

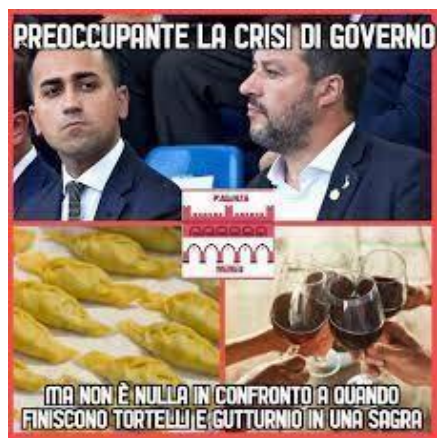

Figure 22: pre-packaged snacks vs coppa

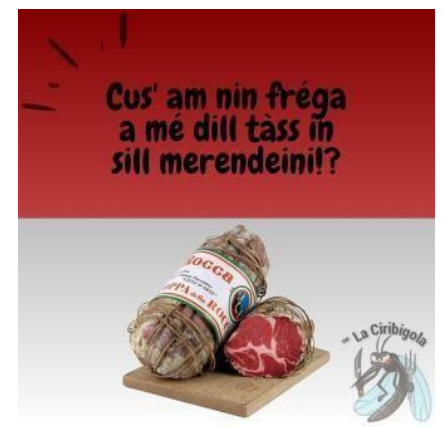

Source: $\underline{\text { https://www.instagram.com/p/B2mOHXSIUlO/ }}$

\footnotetext{
${ }^{4}$ Fresh pasta folded around a filling of minced meat mixed with eggs and Parmisan cheese, boiled and served in meatstock.
} 


\section{9-21 DECEMBER , 2019 LONDON, UNITED KINGDOM}

Source: https://images.app.goo.gl/94Ag8L6jDZLotL8fA ? igshid=hrzq2elvftb5

Once again, we see the incursion of actual dialect in the verbal message of the last meme, where the headline simply states: "Why should I care about the new tax on snacks?" No verbal answer is given to this question, in that the image of the coppa is more than enough to

allow readers to decode the implicature. Traditional dishes represent such an essential part of piacentini's life, that they are, as in figure 23 , what they long for when they are away, and they are compared to the various components of their very blood. The meme in Figure 23, in fact, suggests that red blood cells are made of coppa, white blood cells of pisarei e fasö, ${ }^{5}$ platelets by anolini, fats by the type of cured pork meat called pancetta.
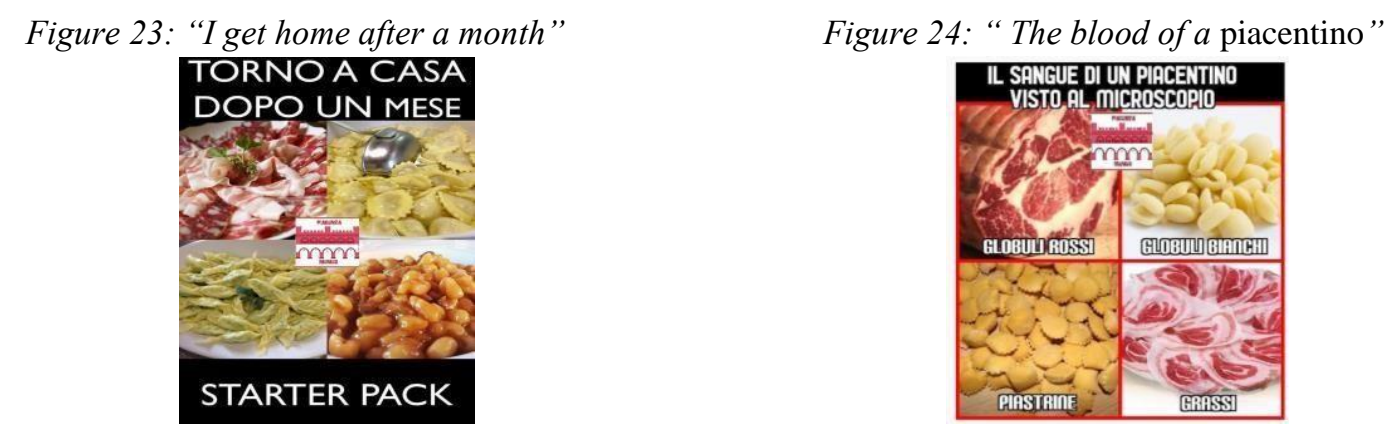

Source :https://www.facebook.com/PiaceMemes/photos Source: http://picpanzee.com/piacenzamemes

\subsection{Discussion}

Naturally, the examples could multiply, in that, as anticipated, new memes are constantly uploaded every hour all over the world. However, even on the basis of the small selection briefly analysed here, it becomes apparent that food-related issues are much more frequent in the memes produced in Italy than in British ones, despite the fact that, as mentioned above, there are various traditional dishes in the United Kingdom as well. Yet, the role assigned to the preparation and the consumption of food plays a completely different role in the two cultures, and although roast dinners are a moment of congregation for British families too, usually they are consumed once a week (generally on a Sunday, hence the expression "Sunday roast" which is often used as a synonym). On the contrary, the moment of family meals within Italian culture is paramount, and often the various members of a family wait for all the other members to be at home before eating. The preparation of food on the part of family members (be they parents, grand-parents, spouses etc.) is considered a demonstration of affection, and the consumption of food is often thought to provide more food for the soul than for the body, constituting both the physical and the metaphorical blood and vital lymph of Italians. Through food Italians begin and maintain social relationships, and precisely because it can be identified as a profoundly social and cultural phenomenon, food obtains a place in any situation. Indeed, as the memes above suggest, food is mostly what Italian people relate to and it often becomes a lens through which the rest of reality is interpreted. This is the reason why, as observed above, issues of food often go hand in hand with issues related to language, that is the cultural and social phenomenon which represents the first and essential "lens" through which we can observe, analyse, describe

\footnotetext{
${ }^{5}$ Fresh pasta, made of small, almost round balls made with flour and breadcrumbs, boiled and served with bean sauce.
} 
and relate to reality. As suggested supra, and as the larger corpus collected for this study confirms, the presence of local dialects in Italian memes relating to food is impressive, whereas in the memes originating in the U.K. the presence of linguistic variants is rather limited. Clearly, this finds at least a partial explanation in the fact that, in Italy, each region/town/village has its own dialect, which distinguishes itself from that of neighbouring regions/towns/villages. Consequently, although - according to Trudgill

(1999) - it is possible to identify sixteen dialectic regions in England, the Italian situation is

far more complex. Dialects, just as food, therefore become extremely distinctive forms of cultural recognition, and are consequently exploited to assert the cultural identity of the members of a community. This, even in the face of globalisation. Indeed, the analysis of the few memes above has demonstrated that while memes, through imitation, repeatedly propose the same cultural units, often relaying on the same global images, characters etc., at the same time they oppose to this global view of the world a very local perspective, whereby the symbols of globalisation are reinterpreted through local (cultural) elements. This holds true from a purely linguistic perspective too. If this is so, it is not only because, as this study has suggested, many memes resort to dialect, but also because, even in the presence of one of the most important means of globalisation - namely the adoption of English as a lingua franca, as witnessed in Figure 23 - Italian memes couple this language with the symbols of local realities. Thus, according to a personal elaboration, the way Italian memes work in terms of globalisation vis à vis localisation could be represented as follows:

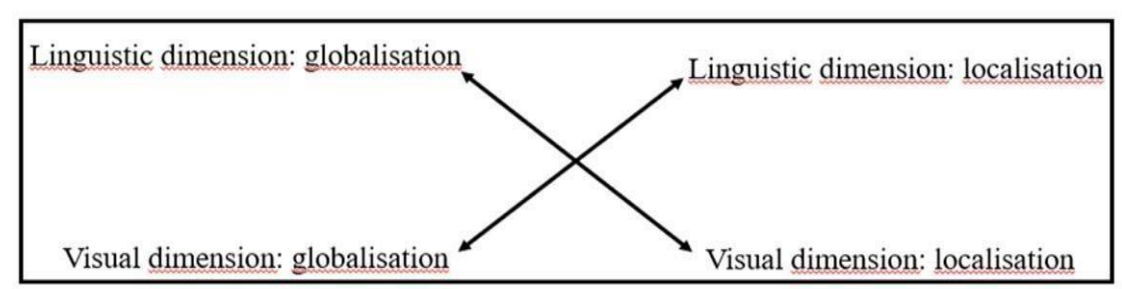

Furthermore - contrary to Scottish memes, which projected very specific images of Scotland, in an attempt to create and perpetuate stereotypical visions of the Scots - through the exploitation of intimately local aspects such as culinary traditions and dialects, memes from Italy overturn some of the stereotypes that usually embody the true "Italian" character, depicting for instance Italians as football fanatics and Latin lovers. In addition, although these memes written in dialect might pose some problem of interpretation to readers who are not conversant with it, it is true that a large part of the memes retrieved provide brief lessons in dialect, offering translations from standard Italian into dialect, thereby giving receivers the chance to appreciate the true identity of the local communities and the memes they create.

\section{Conclusion}

By definition, memes are clearly global phenomena, in that they reiterate some of the cultural icons and symbols that characterise a specific historical period, in a world which seems to be growing smaller and smaller. Yet, this analysis suggests that they simultaneously become strongholds of localisation, from a linguistic and, broadly speaking, cultural perspective. As such, memes become not only the expression of peculiar cultural identities, but they also posit some of the cultural markers people can identify with, thereby enabling the achievement of a (local) identity, despite the general participation in the global culture both the creators and the 
receivers of memes live by. Visual elements and linguistic elements are thus exploited in order to create texts which, despite their apparent simplicity and their often-minimal use of verbal language, are multi-layered and multi-functional. Their primary aim is, of course, to amuse receivers. However, when they do not confirm existing stereotypes, they can be, and are, exploited to assert and simultaneously forge an identity which might be considered truly local, thus attenuating the impact that globalisation has on the societies they stem from.

This appears rather remarkable if we consider memes as a form of expression exploited primarily by young people. In actual fact, the very presence of many memes written in dialect comes as a surprise, in that dialect is usually spoken by older people and its knowledge, for a very long time, seemed to be declining among younger generations. Yet, although Italian youth too is heavily influenced by globalisation - to the point that they have acquired some of their culinary traditions and some of their symbols in terms of dress codes, technology, sporting equipment etc. - the memes collected for this study seem to point to a vindication of local values as well. Indeed, this aspect finds a counterpart in other expressions of Italian society as well, as testified by the fact that - in recent times - courses of dialects in presential and events such as dialect plays in theatres have multiplied.

The memes analysed here therefore point to a hybrid category, between globalisation and localisation, whereby - on the basis of graphic representations like those seen above globalisation cannot exist on its own but, rather than setting itself in opposition to the local realities in an attempt to engulf them, can adapt and morph into a sort of "local globalisation". Clearly, this has important repercussions on the members of our societies and points to their peculiar transformation, implicitly testifying the fact that these types of product are well worth studying, in that they enable us to understand how the world we inhabit is developing.

\section{References}

[1] Dawkins, R., (1976). The Selfish Gene. Oxford, U.K.: Oxford University Press.

[2] Cambridge Dictionary [online] Available: 〈https://dictionary.cambridge.org/dictionary lenglish/meme>. Last access: 13th October 2019.

[3] Merriam-Webster Dictionary [online]. Available: $<$ https://www.merriamwebster.com/dictionary/meme>. Last access: 13th October 2019.

[4] Górka, M., (2014). The meme as an example of carnivalized internet. E-Politikon, vol, 9, pp. 215-242.

[5] Hall, E.T. (1984 [1959]). The Silent Language. New York, NY: Doubleday.

[6] Brake, T., Walker, D.M. \& Walker, T.D. (1995). Doing Business Internationally: The Guide to Cross-cultural Success. New York, NY: Irwin Professional Publishers.

[7] Gatherer, D. (1998). Meme pools, World 3, and Averroes's vision of immortality. Zygon: Journal of Religion\&Science, vol. 33 (2), pp.203- 219.

[8] Doyle, B. (2006). Memography and the Memetic Web. EContent, vol. 29 (1), p. 25. 
[9] Shifman, L. (2013). MIT Press Essential Knowledge: Memes in Digital Culture, Cambridge, Massachusetts: MIT Press, pp. 17- 36.

[10] Hegel, G.W.F. (1977 [1807]). Phenomenology of Spirit. Oxford, U.K.: Clarendon Press.

[11] The University of California Los Angeles Center for Human Nutrition. Available: https://www.uclahealth.org/clinicalnutrition/ >.

[12] Oxford English Dictionary, (2005). Oxford, U.K.: Oxford University Press.

[13] Kress, G. \& Leeuwen, T. (2006). Reading Images: The Grammar of Visual Design, $2^{\text {nd }}$ ed. New York, N.Y.: Routledge.

[14] Trudgill, P. (1999) The Dialects of England, Oxford, Blackwell. 